\title{
Paraplegia
}

\section{Spinal Cord Seizures: A Possible Cause of Isolated Myoclonic Activity in Traumatic Spinal Cord Injury: Case Report}

\author{
J. M. Meythaler, MD, S. M. Tuel, MD, L. L. Cross, MD \\ Virginia Spinal Cord Injury System, University of Virginia Health Sciences Center, \\ Charlottesville, Virginia 22908, USA.
}

\begin{abstract}
Summary
Spinal cord seizures are infrequently reported. They have been associated with intravenous dye placement, transverse myelitis and multiple sclerosis, but never with traumatic spinal cord injury (SCI). We report the case of a 48-year-old SCI male with complete C6 quadriplegia, and apparent spinal cord seizures. These seizures were characterised by myoclonus simplex activity involving the upper extremities only. The lower extremities were spared. The patient was conscious throughout the myoclonic activity and an electroencephalogram of the brain obtained during an event revealed no cortical epiliptiform activity. The seizures lasted approximately 30 seconds to a few minutes, and an acute increase in blood pressure and a decrease in pulse generally occurred 30 to 60 seconds prior to the event. Previously reported spinal cord seizures in multiple sclerosis were frequently treated with carbamazepine. In this case successful treatment was with diazepam. Spinal cord seizures may present in those with traumatic SCI. Benzodiazepines may be useful in the treatment of spinal cord seizures.
\end{abstract}

Key words: Spinal cord injury; Seizures; Myoclonus; Benzodiazepines; Autonomic dysreflexia; Spasticity.

Spinal cord seizures are an infrequently reported occurrence. Most reported cases have been associated with multiple sclerosis (Cherrick and Ellenberg, 1986; Espir and Millac, 1970; Ekbom et al., 1968; Matthews, 1975; Twomey and Espir, 1980; Watson and Chiu, 1979). One case was documented with a spinal cord arteriovenous malformation and intravenous contrast dye administration. Another case was felt to be due to an ischaemic spinal cord event (Ekbom et al., 1968). No cases have so far been reported to be associated with traumatic spinal cord injury (SCI). We describe the unique presentation of a case of apparent spinal cord seizures in a patient with traumatic SCI.

\section{History}

The patient is a 48-year-old male who suffered a C6 SCI in a motor vehicle accident. At the time of admission he was noted to have a $\mathrm{C} 7$ fracture with a bony fragment in the spinal 
canal. Upon admission to rehabilitation he was neurologically graded as a $\mathrm{C} 6$ quadriplegic Frankel class A (Frankel et al., 1969). The patient's clinical course was complicated by episodes of pneumonia. Nine months after his injury the patient developed periodic episodes of involuntary myoclonus of the upper extremities. The patient had myoclonus simplex activity which was arrhythmic and asymmetrical involving the elbow flexors and the shoulder girdle flexors. It involved the upper extremities bilaterally but did not involve the lower extremities. On physical examination the patient was afebrile with no significant neurological changes in his C6 quadriplegia. Each episode lasted from 2 to 5 minutes and consisted of multiple painful myoclonic jerks. The movements occurred in the upper extremities bilaterally, but did not involve the lower extremities. No alterations in the level of consciousness were noted during the episodes. Medications at the time included baclofen $20 \mathrm{mg}$ p.o. q.i.d. Arterial blood gases drawn 2 days before the onset of these episodes revealed a low PCO2 of $4.53 \mathrm{kPa}$ with a normal $\mathrm{PO}_{2}$ of $8.66 \mathrm{kPa}$ and a $\mathrm{PH}$ of 7.42 units. Blood chemistry studies revealed the following values: $\mathrm{Na} 141 \mathrm{mmole} / \mathrm{L}, \mathrm{K} 4.0 \mathrm{mmole} / \mathrm{L}$,

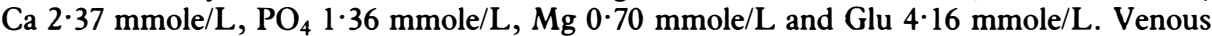
$\mathrm{CO} 2$ was chronically low between 21 to $24 \mathrm{mmole} / \mathrm{L}$. An electroencephalogram obtained during one of these episodes was normal.

Approximately 30 seconds to 1 minute before these myoclonic episodes the patient's blood pressure would rise from a baseline of $90 / 60$ to $140 / 90 \mathrm{mHg}$ and his pulse rate would drop from the mid 90's to the mid 60's. These episodes became more frequent. Consequently, during one episode $2.5 \mathrm{mg}$ of diazepam was given intravenously. This abolished all myoclonic activity but the patient became flaccid and had a 30 second episode of apnoea. We then started him on oral diazepam and increased it slowly to $5 \mathrm{mg}$ p.o. t.i.d. at which time these episodes ceased. When diazepam was weaned the myoclonic activity returned. Diazepam reinstituted at the previous dosage with complete resolution of myoclonic activity once the dosage reached $5 \mathrm{mg}$ p.o. t.i.d.

\section{Discussion}

Paroxysmal neurological disturbances have often been described in multiple sclerosis (Cherrick and Ellenberg, 1986; Espir and Millac, 1970; Ekbom et al., 1968; Matthews, 1975; Twomey and Espir, 1980; Watson and Chiu, 1979). Many authors have felt these to be seizures of spinal cord origin (Cherrick and Ellenberg, 1986; Espir and Millac, 1970; Ekbom et al., 1968; Matthews, 1975; Twomey and Espir, 1980; Watson and Chiu, 1979). These spinal cord seizures have only rarely been described in conditions other than mutiple sclerosis (Uhl et al., 1981; Castaigne et al., 1968). To our knowledge they have never been associated with traumatically induced SCI. Findings in animals suggest that the spinal circuit possesses the ability to acquire new neuronal patterns which can lead to spinal cord seizures (Yu et al., 1984).

In most case reports the neurological activity was localised clinically, as it was in our patient (Espir and Millac, 1970; Ekbom et al., 1968; Matthews, 1975; Twomey and Espir, 1980; Watson and Chiu, 1979; Tokokura et al., 1976; Uhl et al., 1981; Yu et al., 1984; Castaigne et al., 1968). Generally the myoclonus is confined to one or two limbs. These seizures may be associated with painful sensations (Watson, 1979). The patient had a normal electroencephalogram throughout one episode of myoclonic activity. This has been previously reported in patients with spinal cord seizures attributed to multiple sclerosis (Cherrick and Ellenberg, 1986; Matthews, 1975).

This patient had possible contributing factors for developing spinal seizure activity. First he had a low arterial $\mathrm{PCO} 2$ which may provoke seizures by contributing to vasoconstriction and reducing the blood flow to the brain and spinal cord 
(Tokokura et al., 1976). The patient had mild hypomagnesaemia; this has been implicated in the production of cerebral seizures, but usually with rapid changes produced by such conditions as severe fluid losses, not present in this patient (Erickson, 1980). Hypomagnesaemia has been described in SCI (Broughton, 1972). It is often transient and insufficient to produce symptoms. Finally, our patient developed signs consistent with autonomic dysreflexia prior to the seizures. Yarkony, et al., (1986) have documented autonomic dysreflexia as a cause of cortical seizure activity in SCI injured above T-6. It follows that autonomic dysreflexia may cause spinal cord seizures as well as cortical seizures. Other causes of spinal cord seizures have been reported, such as hyperventilation, tactile stimulation, truncal movement, exercise, and hot baths (Ekbom et al., 1968). These types of stimulation have also been implicated in causing autonomic dysreflexia (Erickson, 1980). Whether the autonomic dysreflexia causes spinal seizures or was a part of the seizure activity is open to conjecture.

Carbamazepine has been the drug of choice for treatment of spinal cord seizures associated with multiple sclerosis. Up to now benzodiazepines have not been documented in the treatment of spinal cord seizures, but successful treatment in our case was with diazepam. Diazepam is a documented effective antiseizure medication (Browne and Penry, 1973). It is also an effective antispasticity medication in SCI patients (Young and Delwaide, 1981). Diazepam was chosen because we felt that spasticity may have been contributing to episodes of autonomic dysreflexia which were related to the myoclonic activity. With diazepam treatment they did not recur. Doses were increased gradually so that cognitive and pulmonary side effects could be minimised.

Because diazepam has been frequently used to control spasticity in traumatic SCI, many unrecognised spinal cord seizures may have been diagnosed as spasticity and been treated successfully with diazepam. Physicians treating traumatically induced SCI should recognise that these patients are at risk from the development of spinal cord seizures.

\section{References}

Broughton A, BuRR RG 1972 Magnesium metabolism following spinal cord injury. Paraplegia 10:134-141.

BROWNE TR, PENRY JK 1973 Benzodiazepines in the treatment of epilepsy: A review. Epilepsia 14:277-310.

Castaigne P, Cambier J, Branet P 1968 Spinal sensory-motor seizures. Lancet i:357.

CHERRICK AA, ElleNBERG M 1986 Spinal cord seizures in transverse myelopathy: Report of twocases. Archives of Physical Medicine and Rehabilitation 67:129-131.

EKBOM KA, WESTERBERG CE, OSTERMAN PO 1968 Focal sensory-motor seizures of spinalorigin. Lanceti:67.

ERICKSON RP 1980Autonomichyperreflexia: Pathophysiology and medical management. Archivesof PhysicalMedicineand Rehabilitation 61:431-440.

ESPIR ML, MILLACP 1970 Treatment of paroxysmal disorders in multiple sclerosis with carbamazepine. Foumal Neurology Neurosurgery Pychiatr 33:528-531.

GLASER GH 1982 Cecil's Textbook of Medicine, WB Saunders Co., Philadelphia,pp 2114-2124.

FRANKEL HL, HANCOCK DO, HYSLOP G, et al., 1969 The value of postural reduction in the initial management of closed injuries of the spinal with paraplegia and tetraplegia. Paraplegia 7:179-182.

MATTHEWS WB 1975 Paroxysmal symptoms in multiple sclerosis. Fournal Neurol Neurosurg Psychiatry 38:617-623.

TOKOKURA Y, SAKUTA M, NAKANISHI T 1976 Painful tonic seizures in multiple sclerosis. Neurology 26/2:18-19. 
TwOMEY JA, EsPIR MLE 1980 Paroxysmal symptoms as the manifestations of multiple sclerosis. Fournal Neurology Neurosurgery and Psychiatry 43:296-304.

UHL GR, MARTINEZ CR, BROOKS BR 1981 Spinal seizures following intravenous contrast in a patient with a cord AVM. Annales of Neurology 231:225-230.

WatsonCP,CHIU M 1979Painful tonic seizures in multiple sclerosis: Localization of a lesion.

Canadianfournal NeurologicalSciences 6:359-361.

YARKONY GM, KATZRT, YEONG-CHI W 1986 Seizures secondary to autonomic dysreflexia. Archives of PhysicalMedicineand Rehabilitation 67:834-835.

YouNG RR, DELWAIDE PJ 1981 Drugtherapy: Spasticity. New England fournal Medicine 304:96-99.

YU J, CHAMBERS WW, LIU CN 1984 Introduction of spinal seizures by natural stimulation in cats. Brain Research 299:323-330. 